\title{
An Improved Model for Geostatistical Simulation of Fracture Parameters and their Effect on Static and Dynamic Models
}

\author{
A.H. Etminan ${ }^{*}$ and A. Seifi \\ Department of Industrial Engineering, Amirkabir University of Technology, Tehran, Iran
}

\begin{abstract}
This article presents a method for simulation of continuous and discrete fracture parameters distributions in hydrocarbon reservoirs using Sequential Indicator Simulation (SIS) and Sequential Gaussian Simulation (SGS) methods. Fracture parameters including azimuth, dip and density are integrated with the porosity and permeability values determined in the models. Based on this study we have identified stylolites, occluded fractures, vugs (isolated pores) and open fractures using core data from 13 wells in one of the southern Iranian gas fields. A model is constructed using SIS that contains fractures. This enables us to evaluate the role of fractures in the model enhancing permeability and their predictability in reservoirs. For this purpose, only the fractured blocks of the mentioned model were selected for fractures density, azimuth and dip modeling. Afterward, a novel function named Fracture Effect Factor (FEF) is introduced to calculate the effect of fractures on permeability model in the fractured blocks. For porosity modeling, fractures type model is used as an aid for increasing the accuracy of the modeling so that for the mentioned four fracture types, individual variograms are constructed and porosity estimation in each block is performed based on its related variogram. The proposed model is compared with dual porosity model on a fractured reservoir in South of Iran for a period of 18 years. The results of this research indicate that this method can visualize a more real estimation of dynamic and static behavior of the reservoir.
\end{abstract}

Keywords: FMI log, fracture density, fracture azimuth, fracture dip, Sequential Gaussian Simulation (SGS), Sequential Indicator Simulation (SIS).

\section{INTRODUCTION}

Fractured reservoirs are so complex and their analysis is associated with difficulties. For effective analysis and development of such reservoirs, we need to recognize the role of naturally forming fractures and consider them in our plans for data collection and their analysis, systematically. In spite of the several studies in previous years on the fractured reservoirs, mechanism of the multiphase fluid movement has not been very well understood. In this regard, we can point to the [1] and the concept of the dual porosity model in the fractured reservoirs. The theory of Warren and Root was presented for the single phase flow in the permeable environment which is still in use 45 years later. It was extended by the Kazemi and his research group for numerical simulation of the fluid flow in porous and permeable medium [2]. Afterward, reservoir engineers realized that they should predict the uncertainty for reservoir controlling parameters such as porosity, permeability and water saturation. Solution of the PDE equations during the time without considering the uncertainty had differences with interpreting fractured reservoirs behavior. So, the model which could show the uncertainty of fracture distribution can have an important role in this regard. The methods for quantifying uncertainty have been presented by [3]. Lately, modeling and optimizing of fractures distribution has been analyzed by [4] using object modeling method. In this article, with the use of this idea and with the help of simulation methods we studied uncertainty of fractures and reservoir parameters for reducing the risk

\footnotetext{
*Address correspondence to this author at the Department of Industrial Engineering, Amirkabir University of Technology, Tehran, Iran; E-mail: etminan@aut.ac.ir
}

and improving the production estimation [3-6] modeled flow through disconnected fracture systems. They showed that in disconnected systems (which are almost certainly the most common in the subsurface) that it is fracture length and length distribution that are vital to flow. There is a general similarity between [6] and present work. It is in modeling of fracture parameters network distribution using geostatistics for improving the efficiency of dynamic models. The main difference between this work and Philip et al. is in selection of fracture parameters. They modeled fracture length, length distribution and fracture spacing which have a close relationship with regional stresses in disconnected systems. Fracture length is an important factor for flow, but our main focus will be on modeling and investigating the effect of fracture density, dip and azimuth on fluid flow using Sequential Gaussian Simulation (SGS) and Sequential Indicator Simulation (SIS) methods in one of the Southern Iranian carbonate reservoirs. Kangan and Dalan Formations are the main reservoir units of the studied field which are composed of carbonate rocks (dolomite, dolomitic limestone and limestone with anhydrite nodules). Play type is condensate. Fracture parameters including azimuth, dip and density were calculated based on interpretation of FMI log data. The present study proposes an applied and novel method for studying the the effect of open fractures, which are tectonic in their origin, on porosity, permeability and dynamic models. As a result, the information achieved from the fracture models was included as a constant coefficient on the permeability model. 3D visualizations of the PETREL software were used to show the continuity of reservoir, existence of the flow barriers and high porosity and permeability zones. Finally, dynamic model of the reservoir is used for predicting and studying future production of the reservoir. 


\section{METHODOLOGY}

\subsection{Structural Analysis}

Structural analysis, in which variogram equations are solved, is the primitive phase for regional variables modeling. The techniques such as Kriging or conditional simulation are used to estimate the parameters distribution [7-10]. Most of the conventional geostatistical methods use histogram and variogram parameters of data for predicting data distribution in two and three dimensions. Generally, variograms are calculated in 3 directions including $\mathrm{x}, \mathrm{y}$ and $\mathrm{z}$. Vertical variograms are generally calculated with the use of core or well log data. Unfortunately, in the horizontal direction with limited wells, it is difficult to obtain variograms; but with the aid of sedimentology model, this concern can be addressed. So, type of lithology and sedimentary environment could play an important role in the study of spatial structure or variogram. In this direction, first with the use of SIS method, distribution of the fracture sets is modeled. At the next step, fracture parameters model is used as the condition in estimating porosity and permeability parameters.

Horizontal and vertical variograms are used for determining spatial correlation and anisotropy direction of porosity, permeability and fracture parameters for the long range structures. The variogram is the main factor controlling the conditional simulation. So, for sensitivity estimation, many realizations would be generated. Finally, with the use of dynamic simulation the best model would be selected with regard to structural distribution of porosity, permeability and fracture parameters. It should be mentioned that produced versions of the realizations should correspond to the:

measured data in the wells.

parameter distribution histogram

variogram model.

well production history.

\subsection{Spatial Structure}

Variogram or spatial structure would determine variation of the parameters such as porosity, permeability and fractures distribution in space. It is used for modeling of the regional variables. The semi-variogram $\gamma(\mathrm{h})$ shows the changes of a regional variable ( $\mathrm{z}$ ) as a function of Lag distance between two measuring points of $\mathrm{xi}$ and $\mathrm{xi}+\mathrm{h}$, as below

$\gamma(h)=\frac{1}{2 N(h)} \sum_{i=1}^{N(h)}\left[Z\left(x_{i}+h\right)-Z\left(x_{i}\right)\right]^{2}$

in which $\mathrm{N}(\mathrm{h})$ is total number of the points. In this research, one variable Variogram is used for studying the regional variables [11].

\subsection{Simulation: SGS and SIS}

The main goal of SIS and SGS methods is simulation of a variable in a three dimensional space with 3D network. For the reason that after simulation of each block, its estimated value is used for simulation of other blocks, it is named as sequential simulation [11]. In this method, first the probability distribution of each block is calculated based on the existing information in three dimensional variogram. Then, an amount of probability distribution is chosen randomly to estimate that parameter in the mentioned block. It should be noted that in the normal conditioning simulation, use of standard normal distribution is essential for each parameter. So, at the first stage data were normalized and after the simulation process, all simulated data were de-normalized. Generally, SGS technique is used for estimation of continuous variables such as porosity and permeability in a $3 \mathrm{D}$ space. Steps of the SGS algorithm are described as below $[12,13]$ :

1. Normalization of the original data

2. Calculating variogram of the normalized data

3. Selection of a random path for the cells that will be simulated.

4. Estimation of each cell value based on known and simulated values

5. Choose of a random value of the continuous parameter (such as permeability) from normal distribution. This value would be added to the stimulated series.

6. Steps 4 and 5 are repeated to simulate all the cells

7. De-normalization of the simulated values

The conditional indicator simulation is similar to the normal conditioning simulation. A small difference exists between them. In the conditional indicator simulation there is no need for data normalization. Data are only defined with the 0 and 1 probabilities. The probability of 0 shows lack of the mentioned variable and the probability of 1 indicates $100 \%$ presence of the variable. Steps of SIS algorithm are similar to those of SGS method, with this difference that in SIS there is no need to perform steps 1 and 7.

$$
I(u)= \begin{cases}1, & u \in \text { Variable } \\ 0, & u \notin \text { Variable }\end{cases}
$$

\subsubsection{Fractured Reservoirs Simulation}

Fractures cause difficulty in estimating static and dynamic properties of hydrocarbon reservoirs. Simulation of fractures and their relationship with the matrix block is an important issue in the analysis of fractured reservoirs [1316]. Often, fractures have a complex pattern and are composed of multiple sets. Each set of these fractures may differ from other sets in dip, azimuth and spacing. These sets would be related to the natural stresses. Fractures can be detected on the core samples by macroscopic and microscopic studies. Also, through the especial well logs analysis such as FMI and FMS log data, they can be identifiedm, qualitatively and quantitatively. Such fractures can increase the permeability, significantly and could improve the well production. Therefore, study of fractures and their effect on the static and dynamic models is important. If the fracture model is not included in the static models, well productivity index $(\mathrm{Q} / \Delta \mathrm{P})$ will be underestimated and pressure gradient will be overestimated. Present study proposes a novel approach for increasing the accuracy of static models by integrating them with fracture facies (SIS) and parameters (SGS) model.

\subsection{Analysis of Fractures Nature (Fracture Facies)}

In spite of mechanical stratigraphy, in the fracture stratigraphy approach, we are relating fracture distribution to rock 
or petrologic controls (such as composition, grain size, and porosity) and mapping these rock property distributions in the subsurface [17]. There are several classifications of the fractures based on scale, origin, morphology, tectonic and their effect on reservoir quality. One of the important factors which can affect the fractures is diagenesis. There are several papers that discuss the role of diagenetic processes such as dissolution, cementation, compaction, dolomitization and pressure dissolution on fractures from them works of [18-22] could be mentioned [19] proposed a novel and interesting classification for fractured reservoirs. However, solution of matrix equations using geostatistics is a time consuming process. Also [23, 24], proposed classifications for pore types in hydrocarbon reservoirs.

A good classification of fractures is proposed by [17]. He proposed four fracture types based on of the effects of fracture system to overall reservoir quality as below: Type 1: Fractures provide the essential reservoir porosity and permeability. Type 2: Fractures provide the essential reservoir permeability. Type 3: Fractures assist permeability in an already producible reservoir. Type 4: Fractures provide no additional porosity or permeability but create.

The classification presented in this study is to some extent different from that of [17]. Reservoir rocks were classified into four facies based on presence or absence of the open fractures, pore types, connectivity of pores and their porosity-permeability relationship as below:

Fracture facies 1: matrix or reservoir rocks without porosity and permeability.

Fracture facies 2: rocks with occluded pores or pores filled with cement, such as stylolites and fractures filled with secondary cement (porosity and permeability is very low).

Fracture facies 3: rocks with isolated porosity (noneffective porosity) such as moldic and vuggy porosity (high porosity and very low permeability)

Fracture facies 4: rocks with open fractures and connected pores (very low porosity and high permeability)

This classification can justify diagenesis and its effects on fractures. For example, if cementation occludes the fracture rock will be classified as fracture facies 2 or if dissolution causes moldic pores rock will be classified as fracture facies 3. Also, it could be considered as an efficient way for calculation of fracture effect factor in only fractured blocks of the permeability model.

Several researchers such as [25-31] have tried to investigate the role of micro-fractures in fractured reservoirs. Also, some researcher discussed on indentifying open and seal fractures from them [32-34] can be mentioned. It is necessary to mention that using this classification the role of fracture parameters will be investigated. That is, fracture presence (whether micro or macro-fractures) is important. Because, we will deal with only fractured blocks in the model.

The purpose of this classification is to construct a more realistic model of the reservoir parameters (porosity and permeability). The fracture facies model in combination with porosity and permeability models could provide a better way to acquire much more knowledge of fracture effects on static and dynamic models. In this research, all of the information regarding factures nature and pore types was obtained by macroscopic and microscopic core studies. For microscopic analysis, 1500 thin sections from 13 cored wells were studied. Representative photomicrographs of the mentioned classification (matrix, stylolite, vugs and fracture) are shown in Figs. (1-4). The most important issue in the statistical analysis of fractures is identification of their spatial structure using varigram tool. For this purpose, following codes were assigned to the fracture facies:

Code 0: Matrix

Code 1: Stylolites and occluded fractures with permeability of about 0

Code 2: Isolated pores, vuggy and moldic pores

Code 3: Open fractures and connected pores

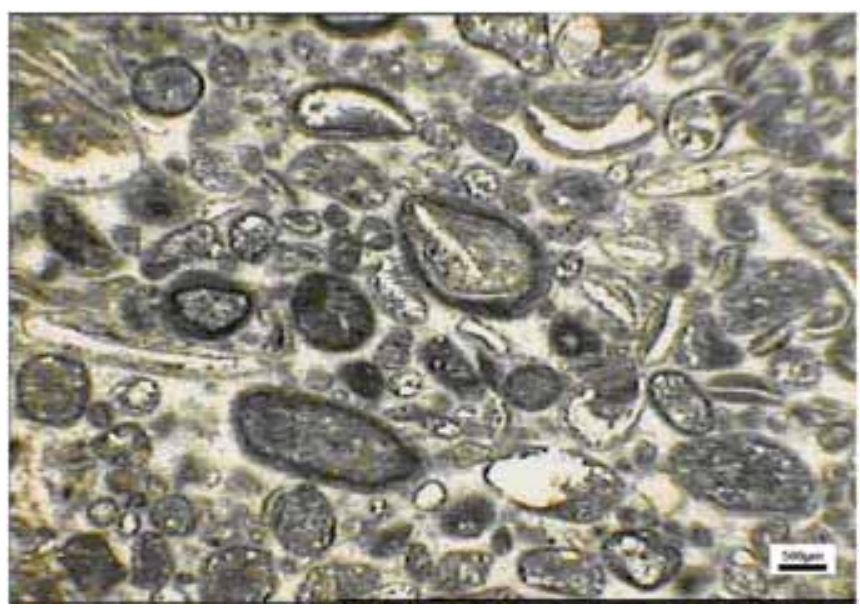

Fig. (1). Potomicrograph showing a sample of matrix (carbonate facies). Porosity and permeability are near zero.

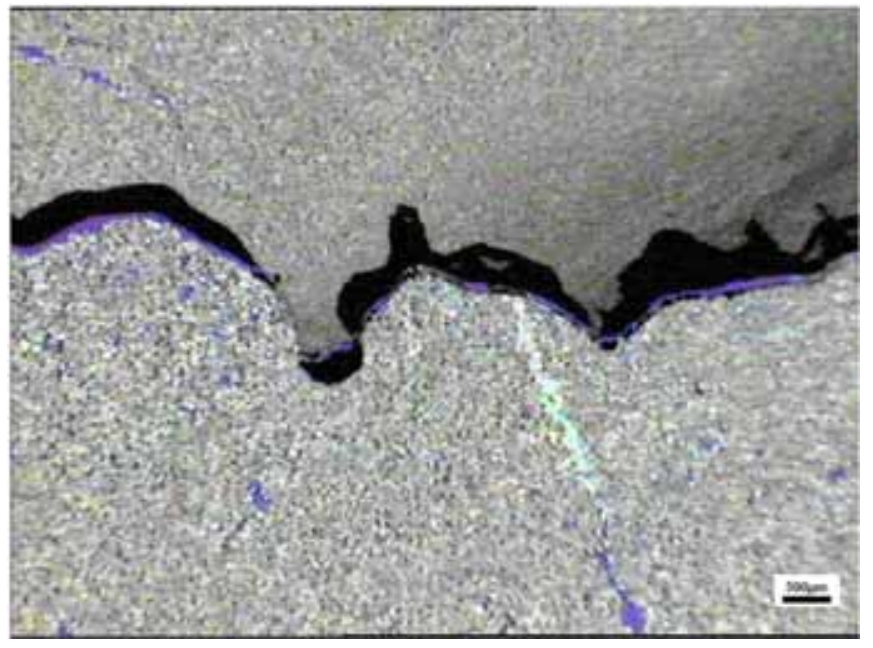

Fig. (2). Photomicrograph showing a sample of Stylolite (carbonate facies). Porosity and permeability are very low.

Variograms of the fracture facies were obtained based on study of 13 cored wells (Fig. 5). Afterward, distribution of the fracture facies was simulated using SIS technique. In Fig. (6) one of the best realizations of the simulation is shown. According to the basics of structural analysis, produced realization should confirm the histogram of the known parameters distribution (Fig. 7). 


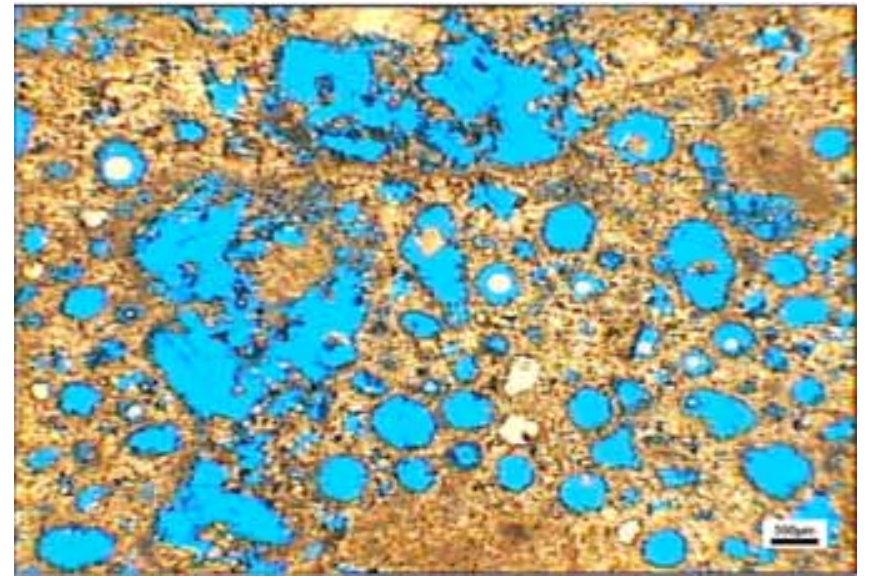

Fig. (3). Photomicrograph showing a sample of vuggy porosity (carbonate facies). Porosity is high and permeability is low.

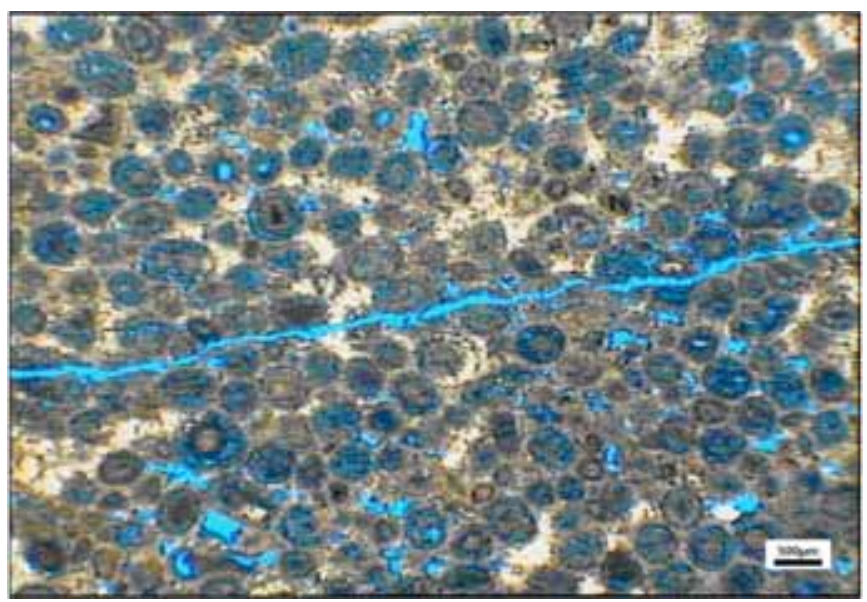

Fig. (4). Photomicrograph showing a sample of open fracture + vugs (carbonate facies). Permeability is high and porosity is low.

\section{RESULTS}

The studied reservoir covers an area of about $21 \mathrm{~km}$ by $40 \mathrm{~km}$ and thickness of the reservoir interval is $95 \mathrm{~m}$. With this consideration, the grid dimensions of the reservoir are defined as 164 block in $\mathrm{x}$ direction, 88 blocks in y direction and 95 layers in $\mathrm{z}$ direction. The dimensions of each block in the mentioned grid are $250 \mathrm{~m} \times 250 \mathrm{~m} \times 1 \mathrm{~m}$.

\subsection{Porosity and Permeability Modeling}

Porosity and permeability are of the most important continuous variables which were simulated in this study. In this research, in order to obtain a more realistic view of distributing pore space in the studied reservoir, fracture facies model was used to improve the porosity model. It means that variograms of porosity distribution were obtained according to the fracture facies model. Horizontal and vertical variograms were calculated for the porosities related to matrix, stylolite, vug, and fracture, separately. Then, in order to estimate porosity in each reservoir block, based on its fracture facies model, the related variogram was used. Porosity of the wells was obtained from analysis of petrophysical data (neutron and density $\log s$ ). Thirty realizations of porosity distribution were obtained using SGS method. The best realization is shown in Fig. (8).

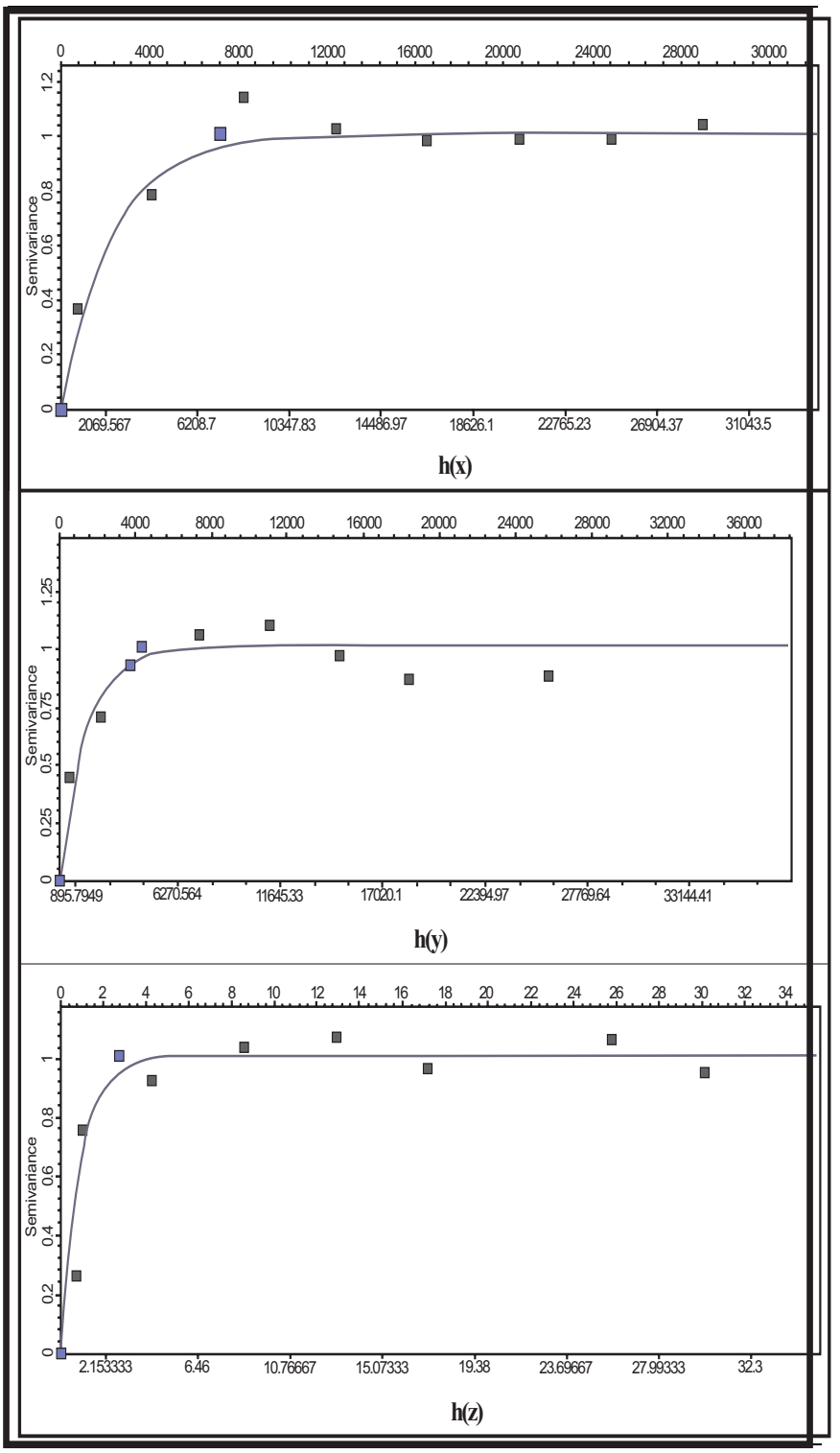

Fig. (5). Variograms of fracture facies in $\mathrm{x}, \mathrm{y}$ and $\mathrm{z}$ direction.

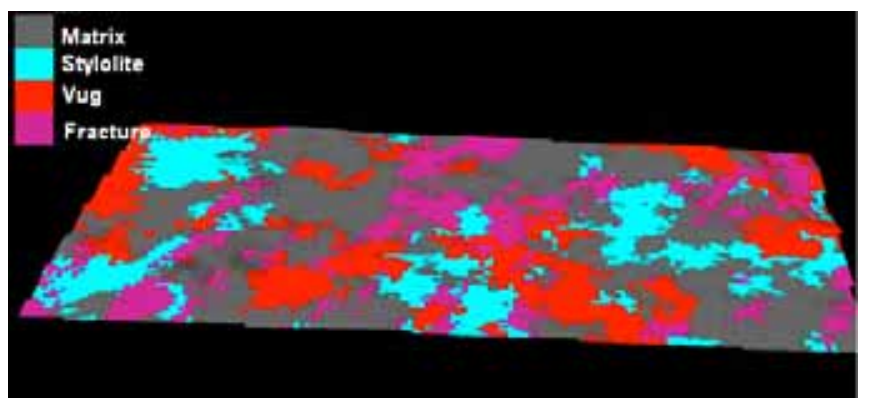

Fig. (6). 3D model of fracture facies.

Core permeability data were available for 13 wells of the studied field. As we will see, at the next stage a coefficient will be calculated for the permeability based on fracture parameters in two horizontal and one vertical direction. Permeability model will be updated based on fracture parameters model in 3 original directions. 


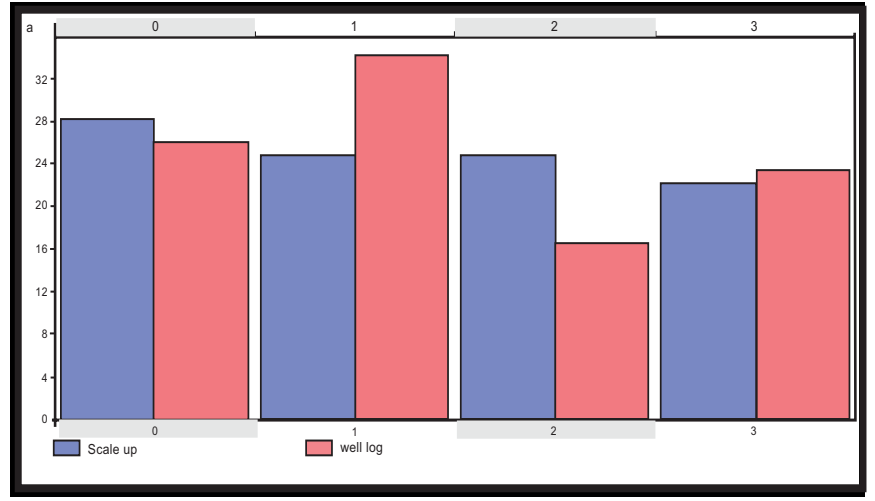

Fig. (7). Histogram of fracture types.

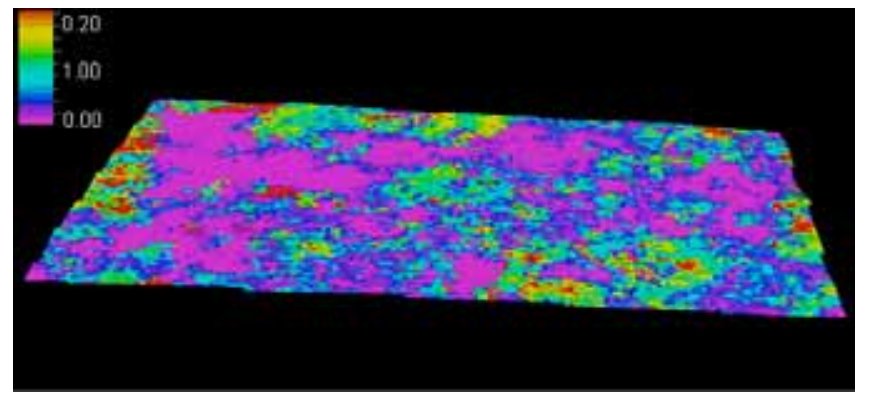

Fig. (8). 3D model of porosity distribution.

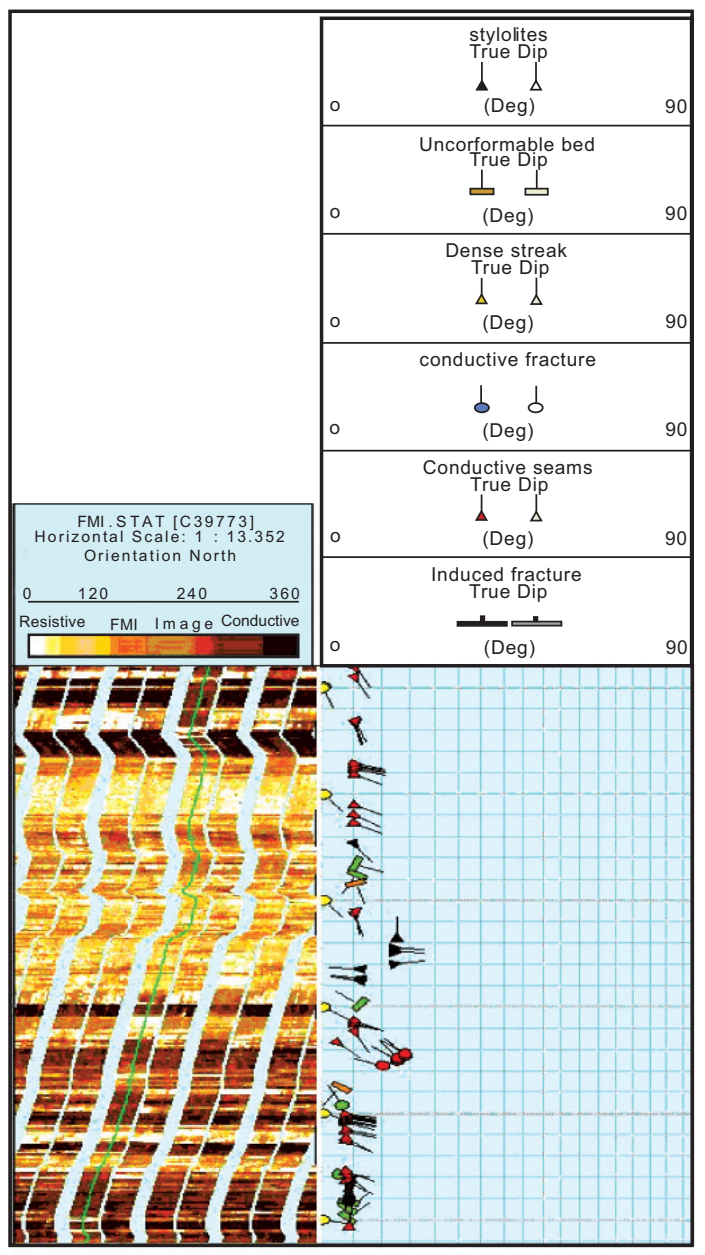

Fig. (9). Results of FMI log interpretation using BorTex software.

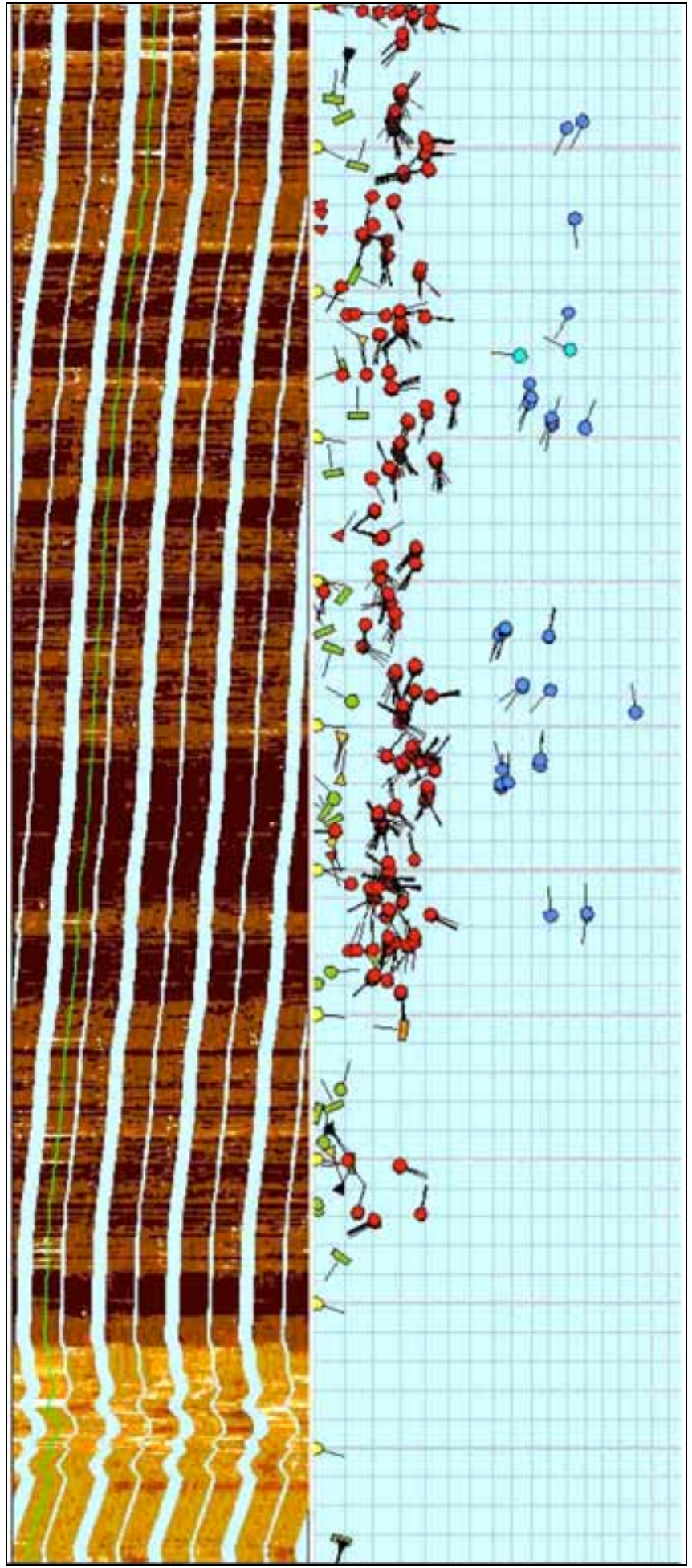

Fig. (9). Results of FMI log interpretation using BorTex software (Cont'd).

\subsection{Fracture Parameters Modeling}

In this study, FMI log data from 7 wells were analyzed and interpreted using the BorTex software and fracture parameters including fracture azimuth, dip and density were calculated. The results of this analysis are shown in Fig. (9) for one of the representative wells. Fracture sampling problem is an important issue in modeling of fractured reservoirs. Selected samples must be enough and representative of 
whole of the reservoir. Several researchers have discussed on sampling problem and have tried to measure fracture parameters as accurate as possible such as [35-37]. Sample rate of calculated fracture parameters using FMI logs is $15 \mathrm{~cm}$. So, there were enough samples of fracture parameters from the mentioned 7 wells. They were considered as representative samples for fractures of the studied reservoir.

The way of fractures distribution within the reservoir in is in relation to the dominant compressional and tensional stresses in the studied area. Rose diagram showing the distribution of fractures azimuth and dip is shown in Fig. (10). In the studied area which belongs to Southern Iran offshore gas field, regional compressional forces are in NW-SE direction, which in turn lead to the distribution of fractures with NESW direction. It is necessary to mention that in some cases azimuth of the fractures may not be aligned with maximum horizontal stress. There are a large number of papers in the literature that state that this is the case; there are other papers that refute that this is a controlling factor in at least a significant number of cases. This is discussed in [38].

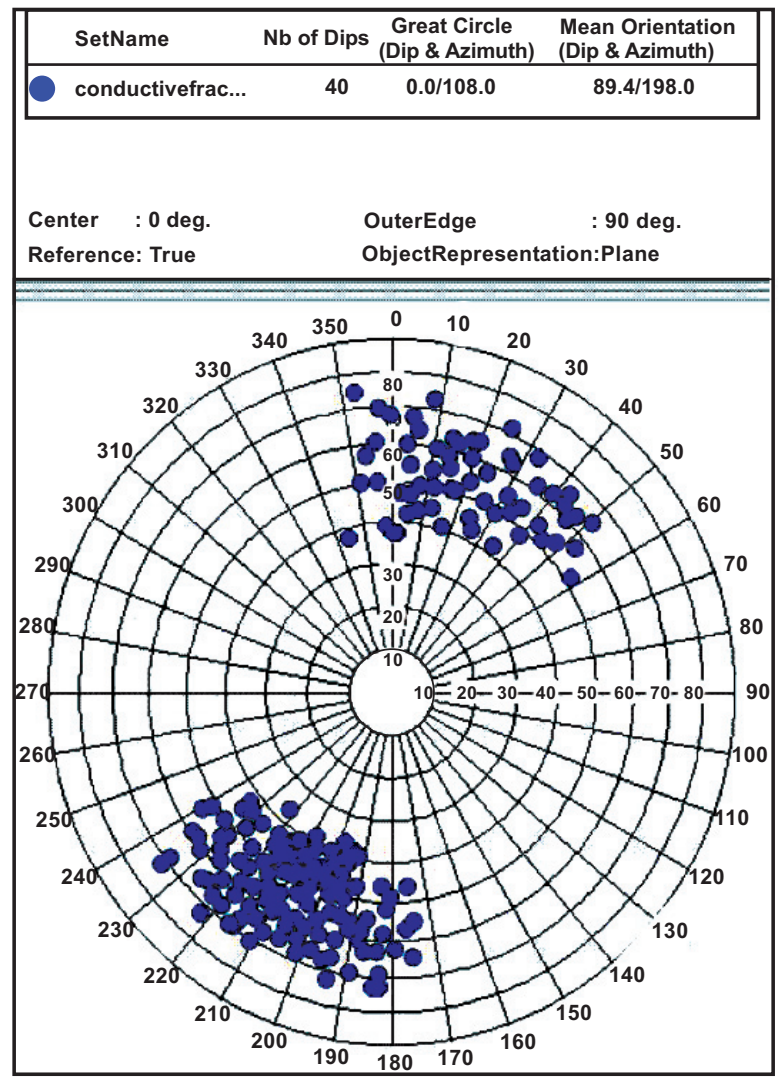

Fig. (10). Rose diagram showing the distribution of fractures azimuth and dip.

The most important purpose in the geostatistical stimulation of facture parameters is calculating fractures effect on the permeability model which will be discussed in the next section. Dip of a variable varies from 0 to 90 . Dip of the fractures in this field varies from 35 to 75 degrees. Therefore, in the range of 35 to 75 degrees, dip of fractures may take a stochastic distribution. It means close points are more similar than distant ones. Azimuth shows more variations. According to the Rose diagram of Fig. (10), based on azimuth two sets of fractures could be identified: 1-fractures with NW-NE direction $\left(350-60^{\circ}\right)$ 2- fractures with SE direction $\left(180-240^{\circ}\right)$. So, at the first stage separation of fractured blocks in these two ranges is necessary. For this purpose, two simple codes were defined, code 0 represents the fractured blocks in the azimuth range of $350-60^{\circ}$ and code 1 represents those in the azimuth range of $180-240^{\circ}$. These two ranges of azimuth in all fractured blocks were simulated through SIS method.

In order to homogenization of azimuth, a variable change in the range of 350-60 was carried out as $\alpha$ correct $=\alpha / 360$. This indicates azimuth of fractures in a unit volume of geological model block. After the azimuth distribution is determined in the two mentioned classes, two models are combined to generate a single model. It is necessary to say in all stages of fracture parameters simulation (fracture azimuth, dip and density); analysis is performed only on the fractured blocks of the model. After the spatial structures of fracture parameters were determined (Figs. 11-13), 3D distribution of azimuth, dip and density of the fractures was estimated through SGS (Figs. 14-16).

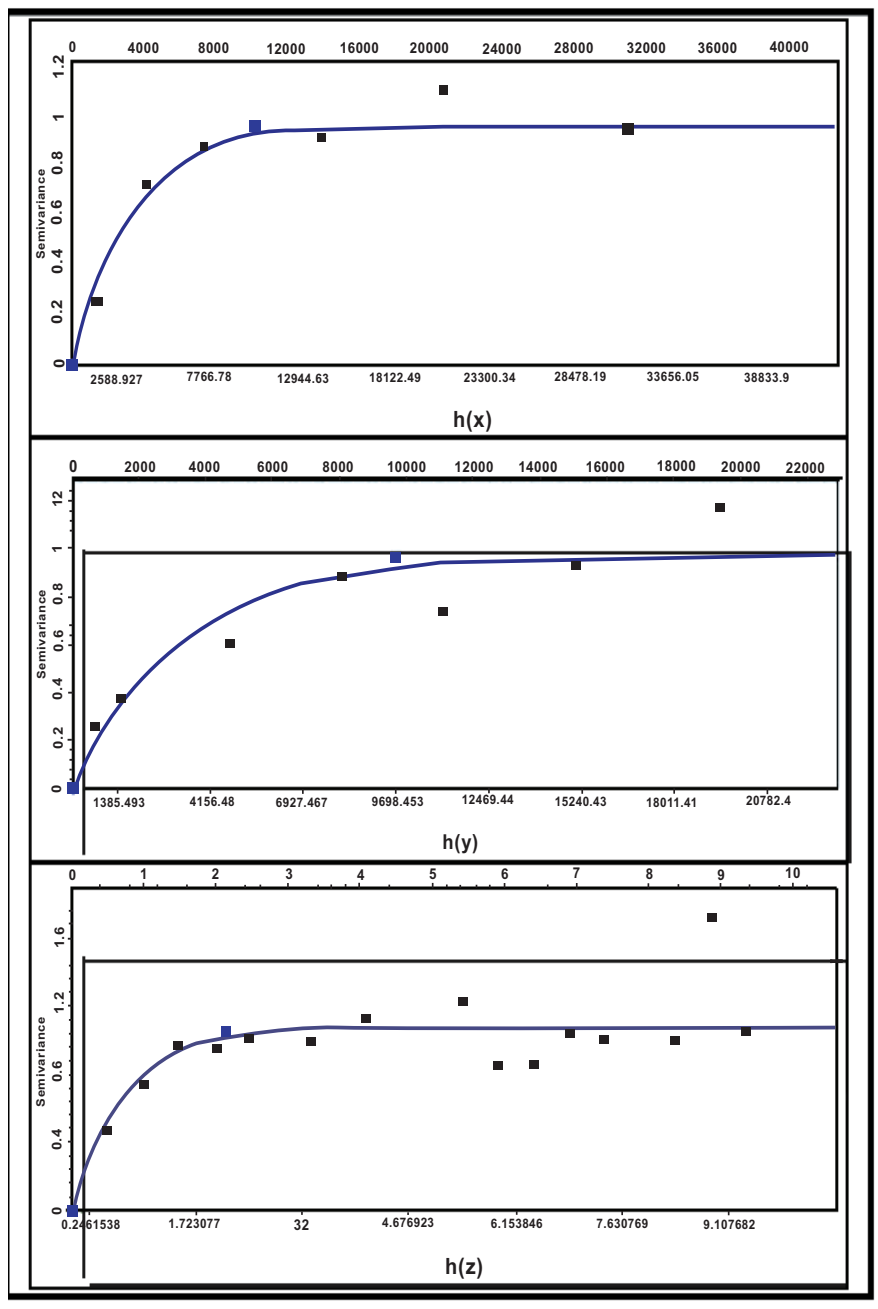

Fig. (11). Variogram of fracture density in $\mathrm{x}, \mathrm{y}$ and $\mathrm{z}$ directions. 


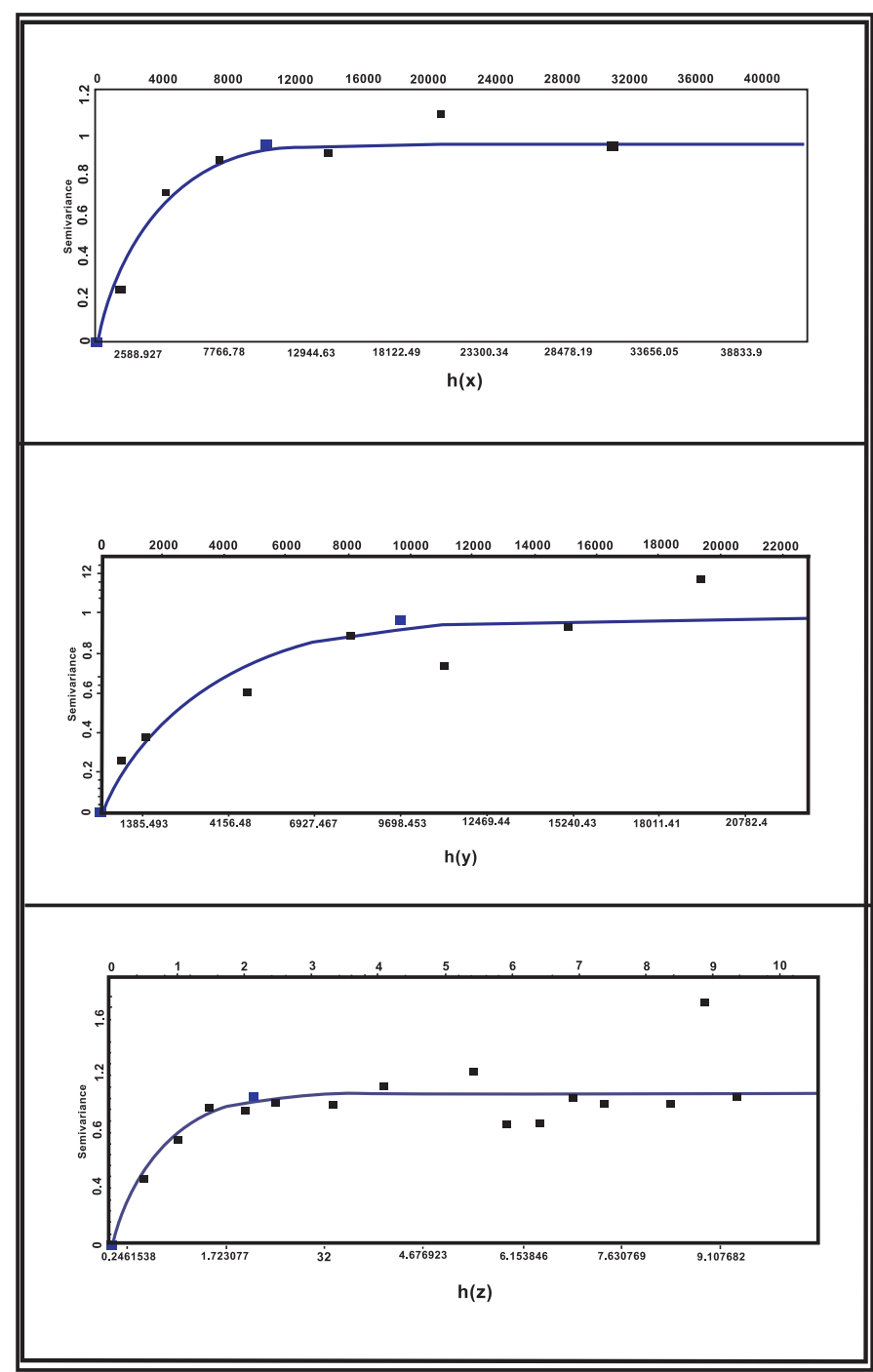

Fig. (12). Variogram of fracture dip in $\mathrm{x}, \mathrm{y}$ and $\mathrm{z}$ directions.

\subsection{Transformation of Fracture Parameters to the Frac- ture Effect Factor}

In this research a new function is introduced to show the impression of the fracture parameters including azimuth, dip and density on the permeability model. This function is named as fracture effect factor (FEF) which calculates fracture parameters as a coefficient in fractured blocks. The FEF function is expressed as below:

$$
\begin{aligned}
& F E F_{x}=1+A \frac{\operatorname{Ln}\left(N_{f}+1\right)}{\operatorname{Ln}\left(N_{f \max }+1\right)}+B \sin ( \pm \alpha) \cdot \sin \gamma \\
& F E F_{y}=1+A \frac{\operatorname{Ln}\left(N_{f}+1\right)}{\operatorname{Ln}\left(N_{f \max }+1\right)}+B \cos ( \pm \alpha) \cdot \sin \gamma \\
& F E F_{z}=1+A \frac{\operatorname{Ln}\left(N_{f}+1\right)}{\operatorname{Ln}\left(N_{f \max }+1\right)}+B \cdot \sin \gamma
\end{aligned}
$$

In this equations, $\alpha, \gamma$ and $N_{f}$ are the azimuth, dip and density of the fractures, respectively. $N_{\text {fmax }}$ is the maximum of fracture density. These are experimental equations showing the role of fracture parameters in $\mathrm{x}, \mathrm{y}$ and $\mathrm{z}$ directions on each permeability block. There is a direct relationship

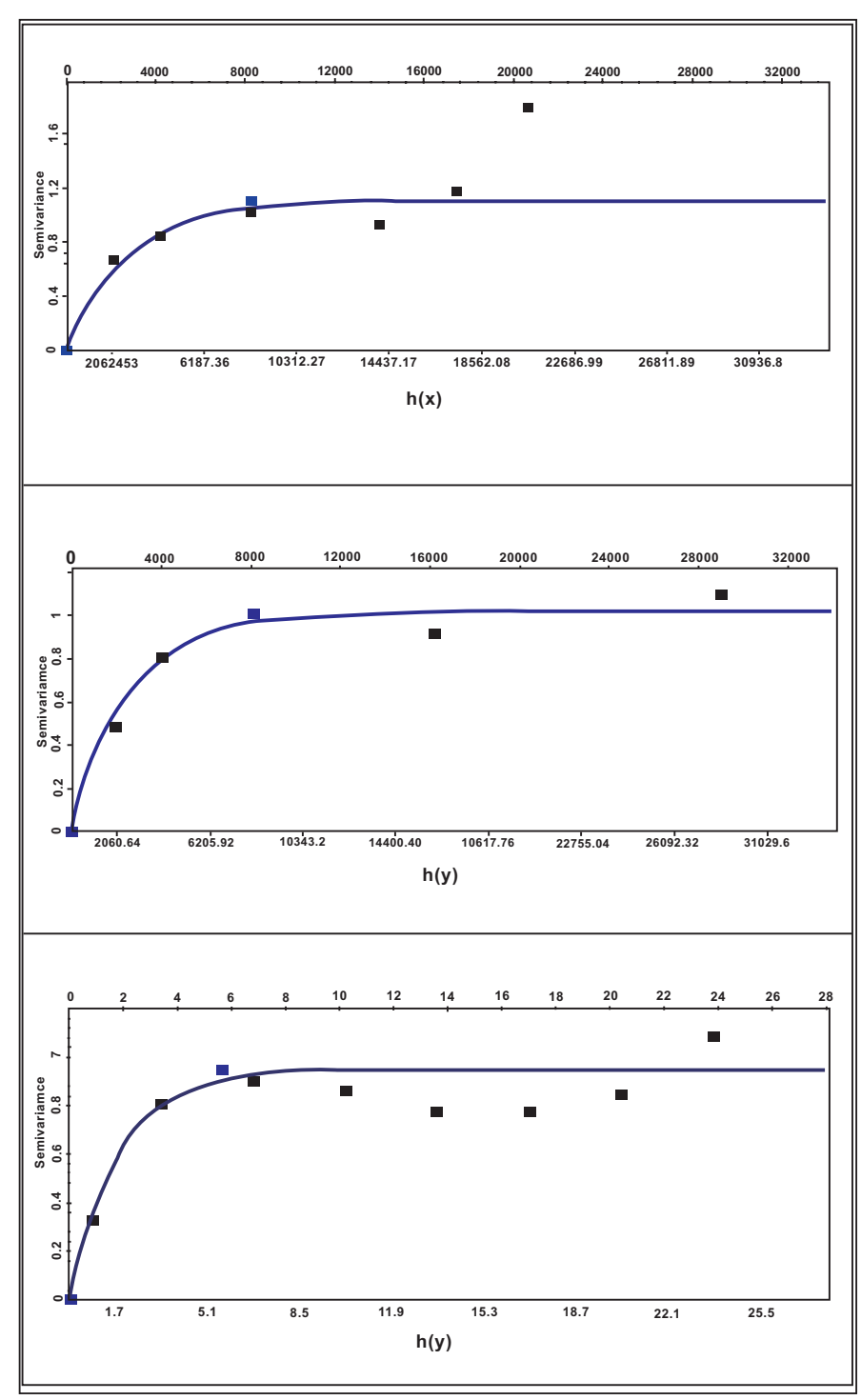

Fig. (13). Variogram of fracture azimuth in $\mathrm{x}, \mathrm{y}$ and $\mathrm{z}$ directions.

between permeability and $\operatorname{Ln}\left(N_{f}\right) / \operatorname{Ln}\left(N_{f \max }\right)$ in three original directions. To avoid division by zero $\left(\operatorname{Ln} N_{f m a x}=0\right)$ or ignoring the role of fracture density $\left(\operatorname{Ln} N_{f}=0\right)$, constant 1 was added to numerator and denominator of mentioned ratio. The role of fracture dip and azimuth was included as $\operatorname{Sin}( \pm \alpha)$.Sin $\gamma$ in $\mathrm{x}$ direction, $\operatorname{Cos}( \pm \alpha)$. $\operatorname{Sin} \gamma$ in y direction and $\operatorname{Sin} \gamma$ (in z direction). Azimuth of the fracture is meaningless in $\mathrm{z}$ direction and was not considered in Eq. (4). Coefficients A and B are constants which were optimized by analyzing the results of dynamic simulation. They play an important role on the results of dynamic simulation. Small values of A and B lead to decrease in the permeability and lower permeability causes less production. As a consequence, results of dynamic simulation will not be matched with production history. Such a conclusion will be vice versa if A and B values are overestimated. So, by optimal fitting between dynamic simulation and production history results, A and B coefficients were determined as 3 and 1.7, respectively.

Three mentioned equations clearly show the impression of azimuth, dip and density parameters of the fractures on permeability coefficient. 


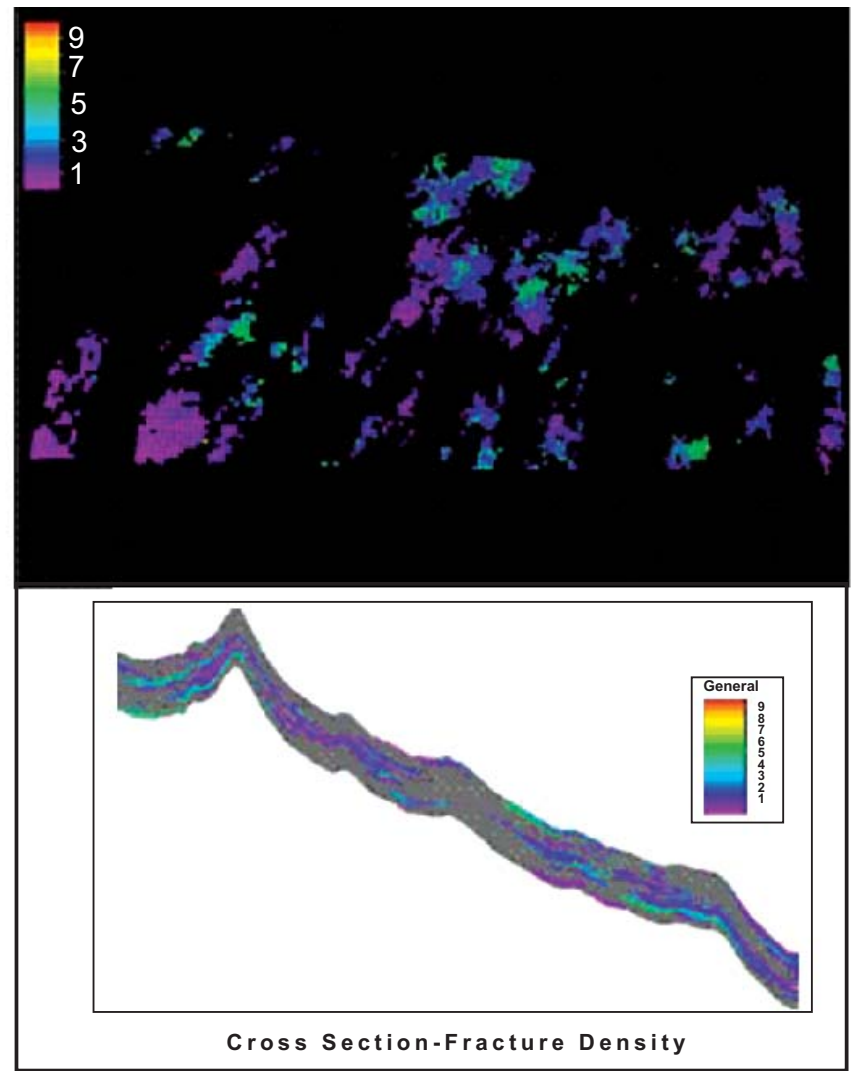

Fig. (14). Cross-section of fracture density in NE-SW direction.
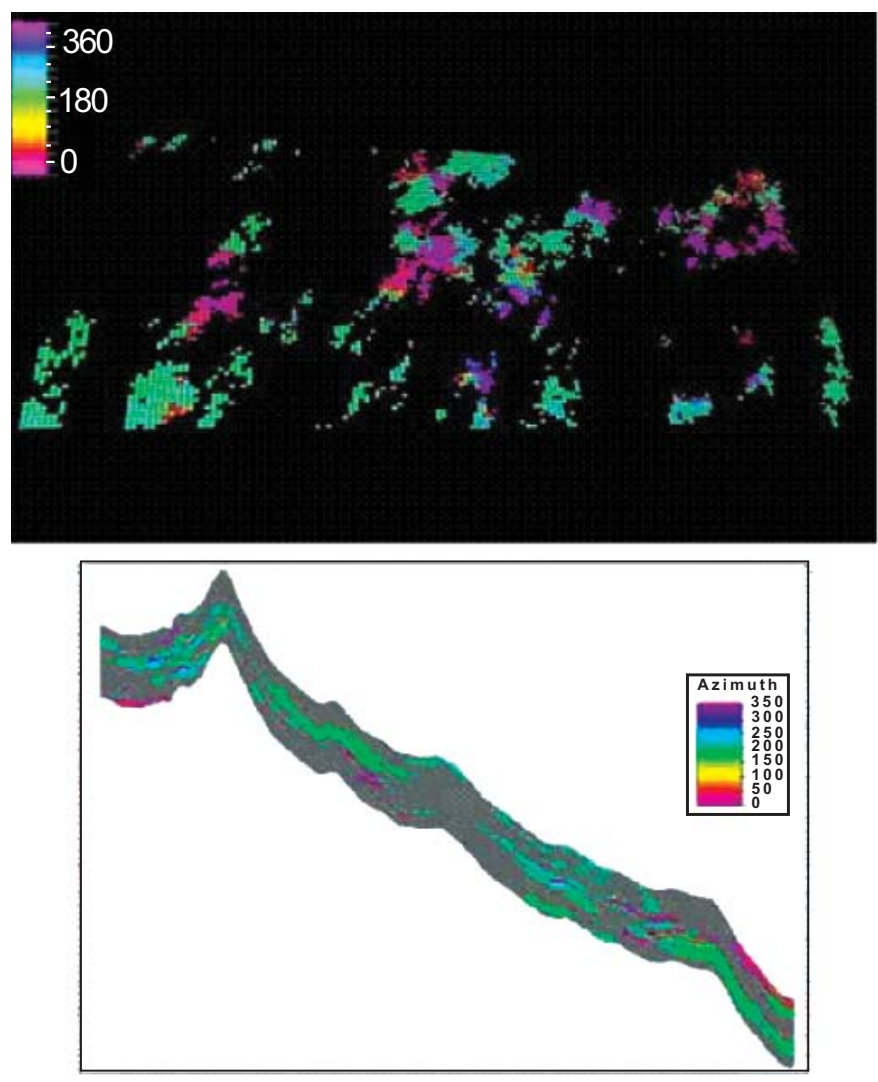

Cross Section-Fracture Azimute

Fig. (15). Cross-section of fracture dip in NE-SW direction showing that fractures dip in crest is higher than limbs. It shows a flexure folding in which fractures in the crest have been developed perpendicular to compressional forces.
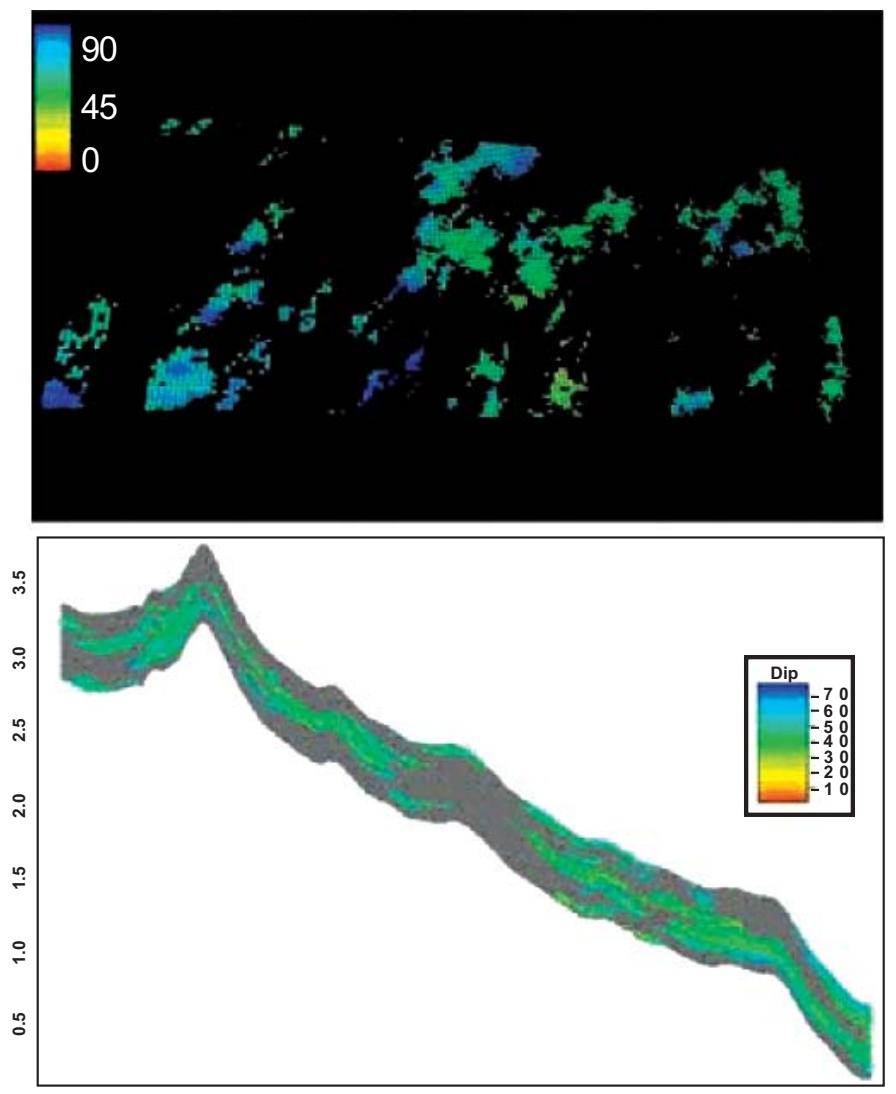

Cross Section-Fracture Dip

Fig. (16). Cross-section of fracture azimuth in NE-SW direction.

At last, by using all of the mentioned functions for every fractured block, fracture effect factor is calculated in three original directions. Figs. (17-19) show the model of permeability in $\mathrm{x}, \mathrm{y}$ and $\mathrm{z}$ directions in which FEF is included.

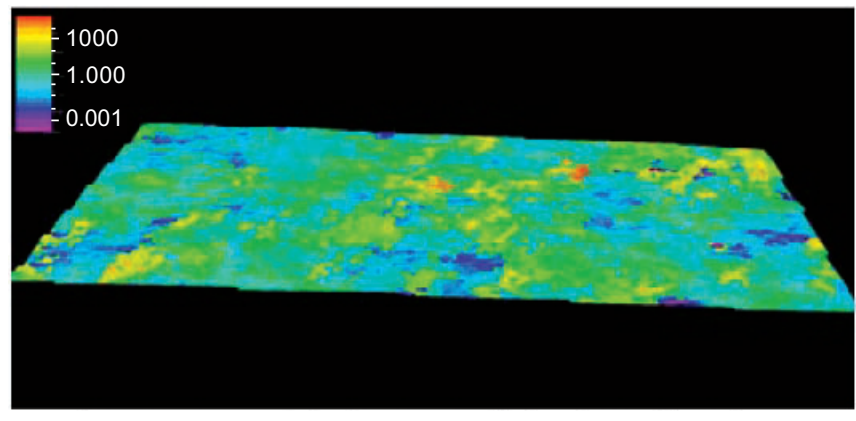

Fig. (17). Model of permeability in x direction.

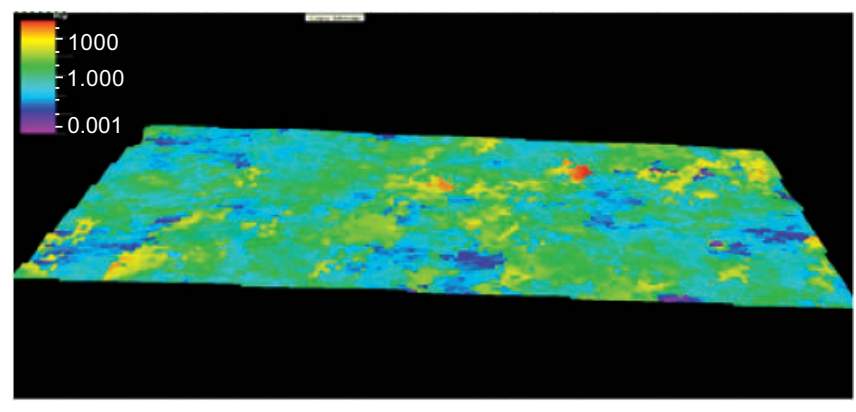

Fig. (18). Model of permeability in y direction. 


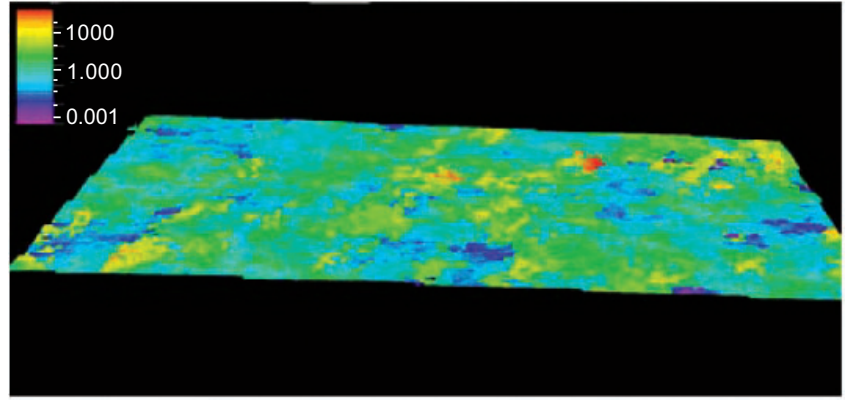

Fig. (19). Model of permeability in $\mathrm{Z}$ direction.

\section{DISCUSSION}

In this work, using petrographic studies fractured blocks were identified and separated for further study. The effect of fracture parameters on permeability model was shown by fracture effect function. After construction of the static models with the proposed methodology, dynamic model of the reservoir was constructed and a comparison was made between performances of the proposed model with that of the dual porosity model for three wells of a fractured reservoir in Southern Iran for a period of 18 years. Figs. (20-25) show condensates production rate and reservoir pressure changes for a period of 18 years in the wells 41,46 and 49 from the studied reservoir. In this simulation, we do not want not to correlate the history with the simulation results. But, our purpose is to compare production rate and pressure change between single porosity model (which its static model is constructed by means of proposed methodology) and dual porosity model, with the same primary reservoir conditions.

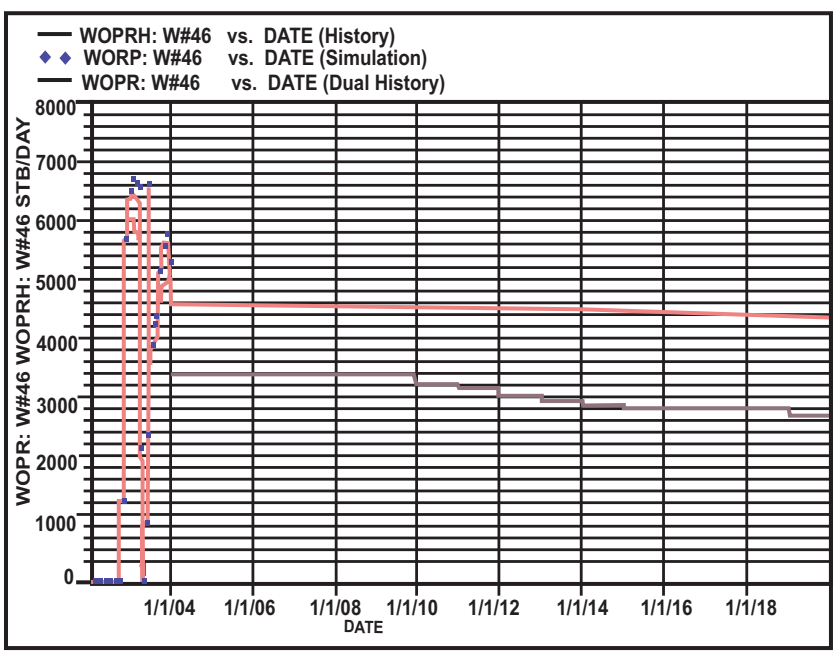

Fig. (20). A comparison between single porosity and dual porosity models for simulating production of condensates in well 46 .

As it can be seen from the Figs. (20-25), single porosity model shows the real behavior of reservoir in the range of production history. But, dual porosity model does not show this behavior clearly and it needs adjustment of the reservoir parameters distribution. The presented results are after the adjustment.

In this study, our purpose is not to reject the application of the dual porosity models for fractured reservoirs simulation. But, it can be claimed that if the fracture parameters role are considered in the constructing static models, single porosity model can be used as a cost effective and time saving method for simulation of the fractured reservoirs. Because, it shows the real behavior of the reservoir for a range of production history very well (gas and condensates production and pressure changers rate).

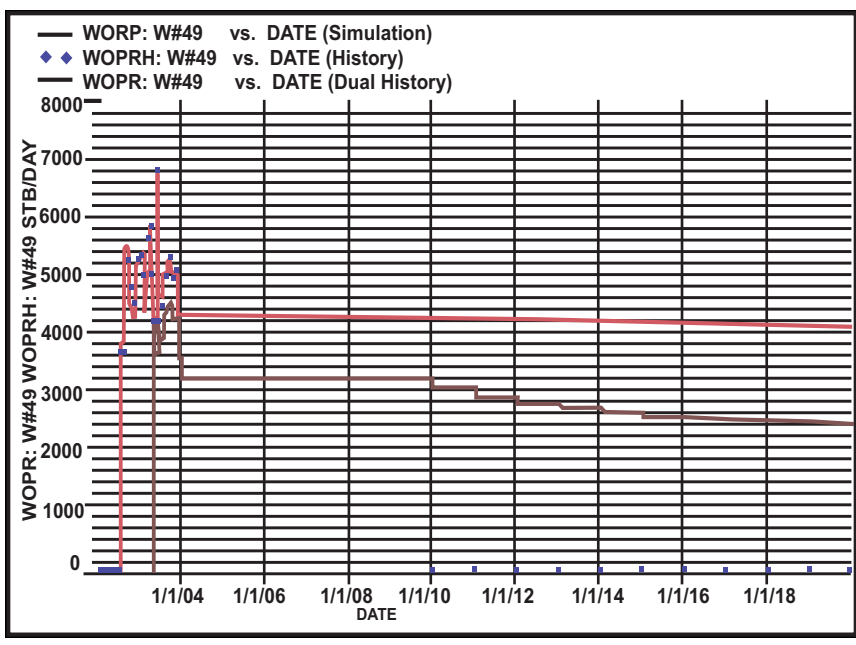

Fig. (21). A comparison between single porosity and dual porosity models for simulating production of condensates in well 49 .

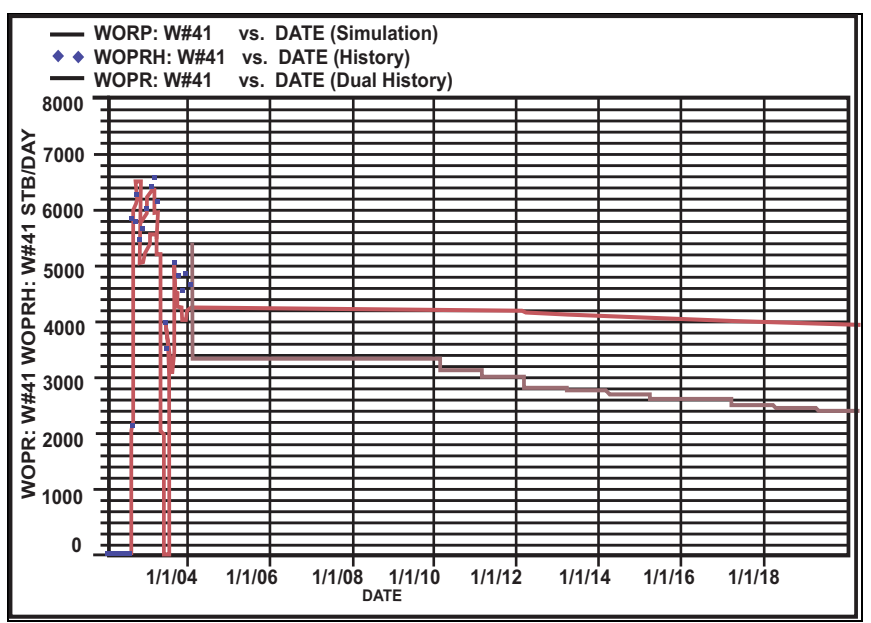

Fig. (22). A comparison between single porosity and dual porosity models for simulating production of condensates in well 41 .

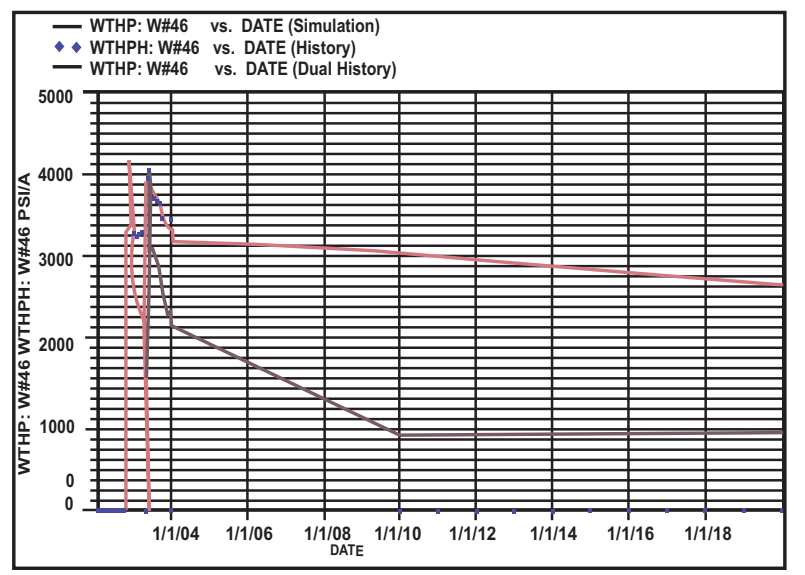

Fig. (23). A comparison between single porosity and dual porosity models for simulating pressure changes in well 46 . 


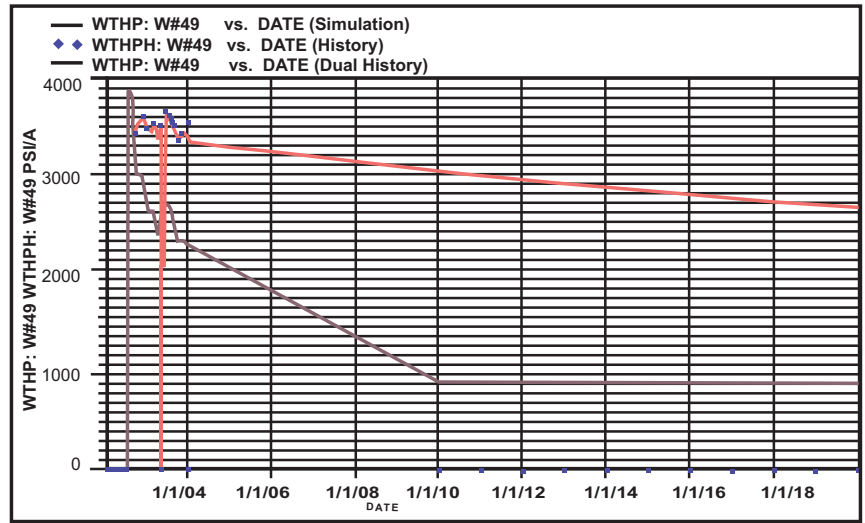

Fig. (24). A comparison between single porosity and dual porosity models for simulating pressure changes in well 49.

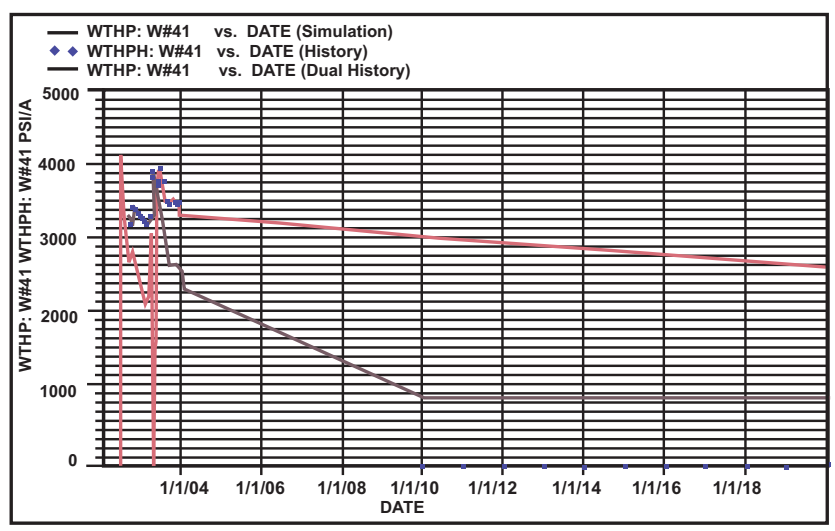

Fig. (25). A comparison between single porosity and dual porosity models for simulating pressure changes in well 41.

\section{SUMMARY AND CONCLUSIONS}

1. Using the macroscopic and microscopic core study, four fracture facies including matrix, stylolite and occluded fractures, vuggy and moldic pores and open fractures were indentified. In this classification matrix is classified as rocks with no fractures and near zero porosity and permeability. This classification aimed at calculating fracture parameters effect on flow in only fractured blokes. Fracture facies were modeled through SIS.

2. Classification of reservoir rocks based on fracture facies and its integration with static models is an effective way for analysis of the fractured reservoirs.

3. Fracture parameters distribution comprising of fracture dip, azimuth and density were modeled using SGS method.

4. An optimal function was introduced for calculating the effect of fracture parameters on the permeability model. This model was used for the simulation of fluid flow.

5. The results showed that optimizing reservoir parameters and fracture parameters distribution with the use of single porosity model is a cost effective and time saving method for simulation of fractured reservoirs. Because, the results of production history and future reservoir behavior and their comparison with well ob- servations confirm the satisfactory results of single porosity model.

\section{REFERENCES}

[1] J. E. Warren, and P. J. Root, "The behavior of naturally fractured reservoirs," SPE Journal, pp. 245-255, 1963.

[2] H. Kazemi, "Improvements in simulation of naturally fractured reservoirs," SPE Paper 10511, Texas, USA, 1983.

[3] P. Abrahamsen, T. Geland, O. Lia, and H. Omre, "An integrated approach to prediction of hydrocarbon in place and recoverable reserve with uncertainty measures," SPE 24276, 1992.

[4] N. H. Tran, Z. Chen, and S. S. Rahman, "Integrated conditional global optimization for discrete fracture network modelling," ELSEVIER, 2005.

[5] D. Clayton, and J. André, "GSLIB - Geostatistical Software Library and User's Guide," second edition, Oxford University Press, 1998.

[6] Z. G. Philip, J. W. Jr. Jennings, J. E. E. Olson, S. E. Laubach, and Holder J, "Modeling coupled fracture-matrix fluid flow in geomechanically simulated fracture networks," SPE Reservoir Evaluation \& Engineering, vol. 8, no. 4, pp. 300-309, 2005.

[7] D. Ponting, "Characterization and modeling of fractured reservoirs (Flow Simulation)," in $9^{\text {th }}$ European Coference on the Mathematics of Oil Recovery, Cannes, Sept. 2004.

[8] S. Amilcar, "Sequential indicator simulation with correction for local probabilities," Mathematical Geology, vol. 30, no. 6, pp. 761765, 1998.

[9] P. Goovaerts, "Stochastic simulation of categorical variables using a classification algorithm and simulated annealing," Mathematical Geology, vol. 28, no. 7, pp. 909-922, 1996.

[10] G. Guo, and R. D. Evans, "Geologic and stochastic characterisation of naturally fractured reservoirs," SPE 27025, 1994.

[11] D. Colin, and M. Dietmar, "Characterization and modeling of fractured reservoirs (Static Model)," Roxar Limited, London, 2004.

[12] L. Guerreiro, "Permeability simulation in poor sampling conditions," SPE 49451, 1998.

[13] L. Guerreiro, and A. C. Silva, "Integrated reservoir characterisation of a fractured carbonate reservoir", SPE 58995, 2000.

[14] J. J. Walsh, J. Watterson, A. Heath, P. A. Gillespie, and C. Childs, "Assessment of the effects of sub-seismic faults on bulk permeabilities of reservoir sequences," Geological Society of London, Special Publications, 127, pp. 99-114, 1998.

[15] R. J. Knipe, G. Jones, and Q. J. Fisher, "Fault sealing and fluid flow in hydrocarbon reservoirs," Geological Society of London, Special Publications, 147, vii-xxi., pp. 87-103, 1998.

[16] F. J. T. Floris, and M. R. H. E. Peersmann, "Uncertainty estimation in volumetrics for supporting hydrocarbon E\&P decision making," Journal of Petroleum Geoscience, vol. 4, no. 1, pp. 33-40, 1998.

[17] R. Nelson, "Geologic Analysis of Naturally Fractured Reservoirs," Gulf Professional Publishing, Houston, Texas, pp. 350, 2001.

[18] J. F. W. Gale, S. E. Laubach, R. A. Marrett, J. E. Olson, J. Holder, and R. M. Reed, "Predicting and characterizing fractures in dolostone reservoirs: using the link between diagenesis and fracturing," In: Braithwaite, C. J. R., Rizzi, G. and Darke, G., eds., The Geometry and Petrogenesis of Dolomite Hydrocarbon Reservoirs. Geological Society, London, Special Publications, vol. 235, pp. 177192, 2004.

[19] S. E. Laubach, and M. W. Ward, "Diagenesis in porosity evolution of opening-mode fractures, Middle Triassic to Lower Jurassic La Boca Formation, NE Mexico," Tectonophysics, vol. 419, pp. 75-97, 2006.

[20] J. E. Olson, S. E. Laubach, and R. L. Lander, "Combining diagenesis and mechanics to quantify fracture aperture distributions and fracture pattern permeability,": In Lonergan, L., Rawnsley, K., Sanderson, D., eds., Fractured Reservoirs, Geological Society of London Special Publication, vol. 270, pp. 97-112, 2006.

[21] A. Makowitz, R. H. Lander, K. L. Milliken, "Diagenetic modeling to assess the relative timing of quartz cementation and brittle grain processes during compaction," AAPG Bulletin, vol. 90, pp. 873885, 2006.

[22] J. E. Olson, Fracture aperture, length and pattern geometry development under biaxial loading: a numerical study with applications to natural, cross-jointed systems. In Couples, G and Lewis, H., eds., Fracture-Like Damage and Localisation. Geological Society of London, Special Publication, 2007. 
[23] G. E. Archie, "Classification of carbonate reservoir rocks and petrophysical consideration," AAPG Bulletin, vol. 36, pp. 278-298, 1952 .

[24] P. W. Choquette, and L. C. Pray, "Geologic nomenclature and classification of porosity in sedimentary carbonates," AAPG Bulletin, vol. 54, pp. 207-250, 1970.

[25] R. M. Reed, and S. E. Laubach, "The role of microfractures in the development of quartz overgrowth cements in sandstones: new evidence from cathodoluminescence studies," Geological Society of America Abstracts with Programs, 28, 7, A280, 1996.

[26] R. M. Reed, and S. E. Laubach,"Density and distribution of microfractures in sandstones: importance to diagenesis. in Bridges to discovery," extended abstracts, volume 2, AAPG Annual Convention: American Association of Petroleum Geologists, A540, 1998.

[27] R. M. Reed, S. E. Laubach, S. J. Clift, J. N. Hooker, and A. Makowitz, "Macrofractures, microfractures, and fracture-cement relations in Permian sandstones from the Val Verde Basin, West Texas," Geological Society of America Abstracts with Programs, vol. 34, 3, A11, 2002.

[28] R. M. Reed, S. E. Laubach, and J. N. Hooker, "The role of quartzlined microfractures in sandstone diagenesis," Geological Society of America Abstracts with Programs, vol. 34, 6, A372, 2002.

[29] S. E. Laubach, R. M. Reed, J. F. W. Gale, O. J. Ortega, and E. H. Doherty, "Fracture characterization based on microfracture surrogates, Pottsville Sandstone, Black Warrior Basin, Alabama," Transactions - Gulf Coast Association of Geological Societies, vol. 52 , p. 585-596, 2002.
[30] S. E. Laubach, "A method to detect natural fracture strike in sandstones," AAPG Bulletin, vol. 81, no. 4, pp. 604-623, 2006.

[31] M. S. Ameen, and E. A. Hailwood, "A new technology for the characterization of microfractured reservoirs (test case: Unayzah reservoir, Wudayhi field, Saudi Arabia)," AAPG Bulletin, vol. 92(1), pp. 31-52, 2008.

[32] S. E. Laubach, R. H. Lander, L. M. Bonnell, J. E. Olson, and R. M. Reed, "Opening histories of fractures in sandstone," Geological Society, London, Special Publications, 231(1), pp. 1-9, 2004.

[33] S. E. Laubach, "Practical approaches to identifying sealed and open fractures," AAPG Bulletin, vol. 87, no. 4, pp. 561-579, 2003.

[34] J. F. W. Gale, and L. A. Gomez, "Late opening-mode fractures in karst-brecciated dolostones of the Lower Ordovician Ellenburger Group, west Texas: Recognition, characterization, and implications for fluid flow," AAPG Bulletin, vol. 91(7), pp. 1005-1023, 2007.

[35] S. Yoshimasa, "Development of fracture size distribution method using trace sampling simulation and AIC", vol. 30, pp. 163-167, 2000.

[36] M. B. Rohrbaugh, Jr.1, W. M. Dunne, and M. Mauldon, "Estimating Fracture Trace Intensity, Density, and Mean Length Using Circular Scan Lines and Windows," vol. 86, no. 12, pp. 2089-2104, 2002.

[37] O. J. Ortega, R. Marrett, and S. E. Laubach, “A scale-independent approach to fracture intensity and average fracture spacing," $A A P G$ Bulletin, vol. 90, no. 2, pp. 193-208, 2006.

[38] S. E. Laubach, J. E. Olson, and J. F. W. Gale, "Are open fractures necessarily aligned with maximum horizontal stress?," Earth \& Planetary Science Letters, vol. 222, no. 1, pp. 191-195, 2004.

(C) Etminan and Seifi; Licensee Bentham Open.

This is an open access article distributed under the terms of the Creative Commons Attribution License (http://creativecommons.org/license/by/2.5/), which permits unrestrictive use, distribution, and reproduction in any medium, provided the original work is properly cited. 